\section{The eve of the 1896 revolution: experiencing Philippine history through immersive and gamified learning}

The eve of the 1896 revolution

Mildred O. Moscoso

Department of Educational Communication,

University of the Philippines Los Baños College of Development Communication, Los Baños, Philippines

Ana Katrina P. de Jesus

Department of Humanities,

University of the Philippines Los Baños College of Arts and Sciences,

Los Baños, Philippines

Renz Frances D. Abagat, Edmund G. Centeno,

Rhodora Ramonette D.V. Custodio, John Mervin L. Embate and

Elijah Jesse Mendoza Pine

Department of Educational Communication,

University of the Philippines Los Baños College of Development Communication, Los Baños, Philippines

Zoilo D. Belano, Jr., Eugene Raymond P. Crudo and

Diosdado B. Lopega

Department of Social Sciences,

University of the Philippines Los Baños College of Arts and Sciences,

Los Baños, Philippines, and

Lexter J. Mangubat

Multimedia Center, University of the Philippines Open University,

Los Baños, Philippines
Received 16 August 2019 Revised 10 November 2019 4 December 2019 6 December 2019 9 January 2020 Accepted 10 January 2020

\begin{abstract}
Purpose - Katipuneros RPG: Bisperas ng Himagsikan (Katipuneros RPG: The Eve of the Revolution) is an immersive and gamified theater that engages its "audiences" in the initiation rites of a secret revolutionary movement in the Philippines in 1896. This descriptive qualitative research evaluates such experiential approach to learning history by investigating the experiences and insights of a group of students from the University of the Philippines Los Baños (UPLB), who participated in Katipuneros RPG.
\end{abstract}

\footnotetext{
(C) Mildred O. Moscoso, Ana Katrina P. de Jesus, Renz Frances D. Abagat, Edmund G. Centeno, Rhodora Ramonette D.V. Custodio, John Mervin L. Embate, Elijah Jesse Mendoza Pine, Zoilo D. Belano, Jr., Eugene Raymond P. Crudo, Diosdado B. Lopega and Lexter J. Mangubat. Published in Asian Association of Open Universities Journal. Published by Emerald Publishing Limited. This article is published under the Creative Commons Attribution (CC BY 4.0) license. Anyone may reproduce, distribute, translate and create derivative works of this article (for both commercial and non-commercial purposes), subject to full attribution to the original publication and authors. The full terms of this license may be seen at http:// creativecommons.org/licences/by/4.0/legalcode
} 
AAOUJ 15,1

Design/methodology/approach - Textual data obtained from the participants' reflection papers and focus group discussion transcripts were analyzed using open and axial coding.

Findings - Three key themes summarized the participants' learning experiences as they went through the play, as follows: (1) Katipuneros RPG as an immersive, interactive and intrinsically motivating medium for learning history; (2) the knowledge, values and skills that served as facilitating factors for their learning and (3) the insights the participants gained about history and life in general.

Practical implications - The research argues that in Katipuneros RPG, learners take on a more active role in studying history as the "teacher" vanishes in lieu of a learning system the allows students to think critically, reflect and collaborate. The approach integrates elements of development theater, immersive play and gamified learning, as well as the principles of constructivist, play-based and multi-sensorial learning.

Social implications - As an innovative learning tool, it is a viable medium to teach history in the current socio-political context of the Philippines.

Originality/value - The study hopes to contribute to literature on pedagogical approaches for teaching and learning history through immersive environments.

Keywords Immersive play, Gamified learning, Teaching and learning history

Paper type Research paper

\section{Introduction}

Gamification that is applied in classroom teaching and learning is not new. However, the application of gamification set in an immersive theater is a fairly recent exploration. Ziechermann and Cunningham defined gamification as "the process of game-thinking and game mechanics to engage users and solve problems" (Kim, 2015, p. 14). Immersive theater, on the other hand, is a kind of theater that invites audiences to enter a fictional world and engage in a multisensory environment (Bucknall, 2017).

Gamification and immersive theater have a common purpose - engagement, which Figg and Japal-Jamini (2009) argue is key, especially for 21st century learners. This matter is of great importance in teaching subjects that are valuable but that which students do not find interesting, such as history. Thus, in this research, a role-playing game that combines the use of game elements and immersive environment is made focus.

The live role-playing game is designed to innovate the way history is taught to students. As an academic discipline, history remains integral to a good understanding of the condition of being human (Corfield, 2008). It enables individuals to gain a guided insight of the present from the events of the past in order to improve the human condition. Unfortunately, at present, there is evidence that suggests a dwindling interest of Filipino students in studying history. A survey revealed that one of the reasons behind this was the belief among 21st century learners that history was "too much about old men and their wars" and that it was exhausting to familiarize themselves with various names and dates (National Book Development Board, 2017).

Thus, it is worth examining innovative approaches that help the young generation to learn about history in an engaging way, such as the Katipuneros RPG. Titled "Katipuneros RPG: Bisperas ng Himagsikan" (Katipuneros RPG: The Eve of the Revolution), this role-playing game (RPG) is an immersive and gamified theater that engages "audiences" in the initiation rites of a secret revolutionary movement in the Philippines during 1896. The play is anchored on constructivist, game-based and multisensorial learning principles. It integrates different elements of theatre, immersive play and gamified learning.

In this paper, the authors sought to describe the learning experiences of a select group of participants in Katipuneros RPG as a medium for learning Philippine history. By studying the experiences and insights gained by the participants and by describing the facilitating factors behind these, this study attempts to address existing gaps in current pedagogical practices and provides useful insights for educators in designing interactive and engaging learning environments.

The world of Katipuneros RPG

Katipuneros RPG is a series of immersive and gamified plays that focus on the Philippine Revolution of 1896. Conceptualized by Filipino cultural creative Gian Carlo de Jesus, it was 
staged by the Balaiwari Immersive and Gamified Experiences at the University of the Philippines Los Baños campus on February 2019 and April 2019, with afternoon and night performances. Balaiwari is a play company specializing in participatory and gamified trainings, play-based team buildings and values formation, immersive tourism, theater for pedagogy and theater for tourism.

In this immersive and gamified play, the audience are treated as player-participants who play roles in historical events of that era. For instance, players have the opportunity to join the Katipunan, the revolutionary movement that led the struggle against Spain. The group would learn the processes and skills of revolutionaries as they undergo simulated Katipunero practices such as participating in covert missions.

The first entry to Katipuneros RPG is Bisperas ng Himagsikan (Dawn of the Revolution). This is set in 1896 and coincides with the actual events of the PhilippineSpanish war. Katipuneros RPG is the first theatre cum transmedia play on the Katipunan and is presented as historical fiction. Chapters 1 to 11 are presented online through videos, blogs, audio clips etc. and are accessible via various social media platforms. Chapter 12 , entitled "Bisperas ng Himagsikan," is a live event, serving as the "theatre part" or the live RPG part.

Players will be immersed in a town called Pulang Tandang, which is celebrating its fiesta. They get to interact with the characters and enjoy the festivities, in real time. Most importantly, there is an option to engage in a quest in order to be accepted in the Katipunan. All tests must be passed while avoiding arrest by the authorities (guardia civil) in order to undergo the Katipunan initiation process patterned after the actual rites of the group about a century ago. In this play, one must become a Katipunero before the Himagsikan or revolution begins.

\section{The Katipunan in Philippine history}

The Philippines was colonized by Spain for more than three centuries, resulting in massive Spanish influences on the indigenous culture. This colonization was met with uprisings, early revolts and reform movements, but it was the revolutionary society Kataas-taasan, Kagalang-galangang, Katipunanng mga Anakng Bayan (Supreme and Venerable Society of the Children of the Nation, also known as Katipunan or KKK), that officially began the Philippine Revolution of 1896. The primary goal of the Katipunan was to gain complete separation/independence from Spain through civil, political and moral objectives. The society believed in the principle of helping oneself and defending the weak and the poor, cultivating good moral character among its members (Agoncillo and Mangahas, 2010).

Upon the discovery of the secret movement by the Spanish government, the Philippine Revolution of 1896 broke out. Inspired by the works and writings of Dr. Jose Rizal on the abuses of the Spanish to Filipinos, the Katipuneros led the armed revolt. "Katipuneros RPG" uses fiction to create a space for players to inhabit this time in history.

\section{Game mechanics and components of Katipuneros RPG}

As audiences enter the play, they are welcomed into a fiesta (fair), specifically the house of the fiesta patron, Don Melecio San Andres. They will then be approached secretly by fiesta game operators, vendors and other fiesta guests who are in fact, Katipuneros in disguise. The audiences will then be oriented about their role as initiates of the Katipunan, and their tasks which are laid out in game cards will be handed to them. Because the objective is to rightfully join the Katipunan, the tasks are designed to gauge the players' knowledge, skills and values. The components of the tasks include the following: social dare tasks, game tasks, historical tasks, Katipunan tasks and decision tasks. Overall, the tasks are designed to elicit the good moral character of the players as they show courage, wit, intelligence, honesty, kindness, 
AAOUJ

15,1

118 resourcefulness and respect, among other values. All these are meant to assess if they are worthy to join the revolution.

Players who will pass the first stage, as demonstrated by the marks they will get on their game cards, should enter the formal Katipunan rites. This part of the play is based on actual historical accounts of the Katipunan membership processes. The initiates enter an old, abandoned house, and they are immediately blindfolded. They then knock on the door of the lodge and are given the signal to enter.

Once inside, the brother president questions the initiates about their background, their motivations and their affiliations. Fake daggers are made felt in the initiates' throat as the leader speaks of the hardships that Katipunan members must endure. Another brother then takes the initiates on a symbolic journey along dark tunnels or across rivers. After this, the initiates are led to a small room draped in black where pictures depicting the fate of the Filipinos under the Spaniards hang on the wall. They are left in the chamber of reflection to ponder upon the images they see. After, they are asked to sit at a desk and answer several questions about the Filipinos' condition in the past, present and future. The final trial is when the initiates are ordered to kill a Katipunan member turned traitor having betrayed the society. The initiates' decision will determine if they can be formally accepted into the Katipunan lodge. This Katipunan ritual is often described as Masonic, and is representative of the journey from darkness to light or from blindness to enlightenment (Richardson, 2013). Courage and loyalty are tested as the brothers emphasize that those who fear or who join out of mere curiosity should not enter the society.

\section{Review of related literature}

The literature review is divided into three sections, namely, theoretical anchors of the design of the immersive and gamified play, immersive theater in education and gamified and immersive learning through RPGs.

\section{Theoretical anchors of the design of Katipuneros RPG}

Constructivism as a learning theory served as foundation in designing this immersive play. This paradigm views learners not as blank slates but as active learners who use their schema to construct and co-construct knowledge with their co-learners, as well as with their teacher. Amineh and Asl (2015) examined the views on constructivist and social constructivist learning and asserted that in social constructivist classes, learners are more active, the learning environments are more democratic and the emphasis is on the learners' interactions. Grounded on this theory is experiential learning, defined as "learning from experience or learning by doing" (Lewis and Williams, 1994 in Schwartz, 2012). Through experiential learning, learners gain opportunities to critically reflect on their learning, and this creates "interdisciplinary learning experiences" which simulates real life situations (Wurdinger, 2005 in Schwartz, 2012).

According to Zosh et al. (2017), play should be joyful, meaningful, actively engaging, iterative and socially interactive. While play-based learning happens usually in children's education, Tanis (2012) found in his dissertation that adult learners "identified cognitive gains in terms of engagement, retention, and understanding” (p. 3). Findings also revealed that adult learners not only found play-based learning as fun and enjoyable but also perceived play and playfulness as creating a learning environment where they feel it is safe to take risks.

In addition, play-based learning should engage the learners' five senses to be experiential and memorable. According to Aja et al. (2017), multisensorial or multisensory learning "is the simultaneous use of visual, auditory, and kinesthetic-tactile to enhance memory and 
learning" (p. 15,114). As a design principle, this creates opportunities to effectively engage students with diverse learning styles, from visual to kinesthetic.

There have been varied identified effects of the use of multisensorial learning to students. Stoffers (2011) studied the impact of multisensory teaching approach to a second-grade class and found that students become "engaged in their learning and were eager to complete more work than was required" (p. 80). It was also noted that multisensory teaching creates positive classroom environment, and this fosters collaboration, excitement to learning and construction of meaning (Stoffers, 2011).

\section{Immersive theater in education}

Similar to changes in interactivity in society due to new media, theater in education has likewise evolved. In the United Kingdom, drama educator Dorothy Heathcote conceptualized the Mantle of the Expert approach where learners have to work together to carry out tasks that allow them to explore an issue aligned with the curriculum objectives. Aitken (2013) writes that this approach taps on three teaching modalities, namely, inquiry learning, drama for learning and expert framing, which positions learners as experts.

In the Philippines, a people's theater is created "to help produce a new generation of Filipinos endowed with a limitless sense of imagination, pride of place, love for country, and a sensitivity to care for fellow Filipinos and fellow humans..." (Philippine Educational Theater Association, 2019).

Nonetheless, the application of immersive theater in education is quite new. According to Bucknall (2017), immersive theater "is a term that has been popularized in recent years to identify a mode of practice that invites ambulating audiences into a fictive world," and is typically "constructed out of expansive, multisensory environments" (p. 1). In this kind of theater, audiences enter a world and interact with various performance elements such as actors, co-players, spaces, stories and roles. One study that examined history learning through interactive performance is that by Evans (2013). She asserts that the personal process of understanding history may be facilitated by using interactive theater in museums.

What is unique about immersive theater is that it places the audiences at the heart of the action, activated by stimulating environmental elements. According to Bouko (2014), audiences "are linked to the story and become an essential part of the imaginary world" (p. 267).

\section{Immersive and gamified learning through RPGs}

Immersive learning is often associated with simulations. Simulations were first introduced in higher education around 2003, but it was in the 1990s when it was first used in the military and in medicine. The idea of immersive learning is to "combine simulation, pedagogy, and 'hard fun' to create a truly engaging and behavior-changing form of learning" (Beckem and Watkins, 2012, p. 62). Immersive learning is grounded on social constructivism as it believes that learners are complex and multidimensional. They must be actively engaged in the learning process in order to construct knowledge jointly in a social context. Also, these kinds of immersive learning empower learners to connect their existing competencies with new knowledge acquired driven by their experiences in the learning environment (Beckem and Watkins, 2012). This implies that students gain a greater sense of agency in their learning.

When learners possess agency in learning, engagement and motivation are inevitably present. According to Fatih et al. (2018), these two factors impact students' learning processes, making the motivating elements in games effective in learning contexts. In said study, the authors looked into the viability of mobile technology-based gamification in teaching History, evaluating students' learning performance in terms of explicit, advanced 
AAOUJ

15,1

120

and tacit knowledge. They concluded that gamification can make the "educational content delivery spontaneous and fun as much as possible" (p. 162, 2018).

In addition, the power of gamification is said to be its ability to attract the learners' attention, immerse and engage them in a given activity and change their attitudes and behaviors (Kim, 2015). Carefully designed games can tap the personal desires of individuals and eventually harness social good.

The vast applications of gamification may be attributed to the changing viewing habits of the audiences in today's digital culture and thus has permeated even the field of the performing arts. Schippers (2017) contends that audiences are increasingly becoming coproducers of a theater performance. From mere theater spectators, audiences are accorded more interactive and performative roles, and one way to achieve this is through gamified theater. Kaiko (2015) affirms this, positing that gamification in theater is not a trend that will soon pass; rather it is a constant consideration when designing the theater-going experience. He further mentioned that the intrinsic motivators present in games, namely, autonomy, mastery, purpose, progress and social interaction, are also factors that motivate people to experience theater.

In this research, Katipuneros RPG becomes the live role-playing game format that interweaves immersive design and gamification. Although role-playing is an earlier model developed in the 1960s, making it a live game is fairly recent. Almost similar with the playbased learning, role playing games provide the "player" or the learners roles that they will have to portray. Role-playing games or RPGs can be identified under game-based learning or gamification of learning as game-based learning uses games to promote cognitive, attitudinal or psychomotor change. There are numerous studies on the effectiveness of RPG in learning. Randi and Carvalho (2013) evaluated its use in the undergraduate medical students in Brazilian public universities. Quantitatively, they found that the majority of the students viewed RPG as an effective tool for learning cellular biology. Results revealed that the RPG approach was well-accepted as it promoted active learning and effective knowledge construction. Moreover, Cook et al. (2017) found that RPG promotes powerful learning affordances to literature. In another study about RPG among middle school students, it was found that the use of RPG had a positive effect on the intrapersonal intelligence of the students (Li et al., 2013). These studies show that RPG promotes active learning and effective knowledge construction, making it a promising educational tool.

Overall, the literature review sheds light on the applications of immersive theater, gamification and role-playing games in education. It also reveals the various principles that characterize experiential, immersive and gamified learning. Through the review, it was also known that some still view gamification as a passing fad, and not much has been written about its systematic application in educational contexts. Having described the world of Katipuneros RPG and the game components, making sense of the qualitative data in light of the said pedagogical principles can now be carried out.

\section{Methods}

The study used a descriptive approach to qualitative research by describing the experiences of participants in Katipuneros RPG, an immersive play that presents historical facts on the eve of the 1896 Philippine revolution.

Fifteen students of the College of Development Communication, University of the Philippines Los Baños enrolled in the second semester, academic year 2018-2019, who attended the Katipuneros RPG participated in the study. These students were requested to write reflection papers detailing their experiences, learnings in Philippine history and insights on the play as a medium of storytelling, of learning history and of learning values. After, they were also requested to take part in a focus group discussion (FGD), with the same 
questions as a guide, to further probe answers in their papers. Meanwhile, the research team from the College of Development Communication, who also participated in the Katipuneros $\mathrm{RPG}$, engaged in group discussions to share their experiences and insights on how the play as a medium can promote learning among students.

Thematic analysis was used in analyzing the data gathered. Data were analyzed on two levels as follows: open coding, wherein data from the reflection papers and the FGD were initially coded followed by axial coding, in which codes identified from open coding were grouped into emerging and related themes. The final themes and the codes within these were agreed upon by the researchers during a workshop, ensuring interrater reliability.

\section{Results}

Results show that the participants' learning experiences during the immersive play may be categorized into three themes as follows: (1) the immersive and gamified theater play as a novel medium; (2) the knowledge, values and skills that served as facilitating factors for their learning and (3) insights gained about history and life in general.

\section{Katipuneros RPG as a novel medium for learning history}

Study participants have generally found Katipuneros RPG as a relatively new medium for learning history, especially since its characteristics and affordances as a learning medium were highlighted in the FGD and in their reflection papers. Comparing it to the more traditional learning media they used in school, the students were not only able to share how the immersive play facilitated the learning of history, they were also able to locate the learning domain that was most effective.

It can be gleaned from the students' insights that various media-object, presentation and publication media (Cadiz, 2003) - had been used to facilitate learning of historical concepts in their classes. From the students' answers, two functions of media may be concluded as follows: (1) media as instructional aid and (2) media as an evaluative tool. Media as instructional aid emerged from the students' description of the learning media their teachers used to deliver lessons on history. These would include lecture powerpoints, documentary videos, photographs, memes, cartoon drawings, textbooks and museum artifacts. On the other hand, various media were also used in their previous history classes as learning assessment and evaluation tools. Some of these tools were prepared by their teachers, such as the questions and presentations for quiz contests. On the other hand, other media, like diorama, artworks, report presentations and video-recorded presentations, were constructed by students through their teacher's instructions to construct.

When asked what they thought about these methods, students' reactions were generally mixed. On the one hand, some said that they enjoyed the engaging and participative nature of media because it made discussions less boring and gave them a sense of agency and motivation; on the other, some disliked the excessive activity they had to put in. Student $\mathrm{H}$ shared that the illustrations drawn by his teacher were effectively used to structure specific narratives in their history lesson, even enabling him to make the lesson more entertaining. Student K, on the other hand, narrated her experience of recording a video of her acting as Juli (female character) in El Filibusterismo and then uploading it on Facebook. She said she found it an embarrassing format for a media output.

It should be noted that the above-said media lend themselves to varied degrees of interactivity and participation on the students' end. Despite that media such as lecture presentations and textbooks may be conceived as merely transmitting information to passive students, role plays and quiz contests provide opportunities for students and teachers to interact and discuss. Some, however, may be used to fulfill both purposes - a video 
AAOUJ 15,1 documentation about a war can be said to merely transfer information to a student. But a video documentation of a student reflecting about a war or dramatizing events in a war elevates the medium into one which students can manipulate and control on their own in order to learn.

The discussions in the earlier paragraph provide a condensed narration of the media these students had been used to when studying history in previous classes. The discussions that follow will revolve around Katipuneros RPG as a novel medium for learning history based on these students' accounts, essentially providing a stark contrast to what these students had been exposed to before.

Immersive: creation and simulation of a world. One usual description of the students about RPG was its immersive nature as a learning medium, that is, Katipuneros RPG facilitates the creation and simulation of a world. Data from the students' reflection papers and focus group discussion point out that they enjoyed the medium's production design and its ability to accurately simulate the events that occurred during that period, effectively immersing them in it. The students attributed this feat to the realistic portrayal of the place, props and attire the convincing acting of the guardia civils and the tinderas in the perya stalls and the use of traditional, folk Filipino music as backdrop to the fiesta. These, from their point of view, contributed to the realization that the RPG was indeed a novel medium in learning history as most of their history classes lacked not only a rich description of the events during that period but also a means to transport them through time and experience historical events themselves. The realism in the costume and set design of the RPG were "quite convincing" and allowed the participants to be transported "to another world."

In particular, the students praised the acting done by the civil guards (guardia civils) whom they narrated to be glaring all the time and snooping around whenever they sensed a possible assembly of rebels. The facial expressions and the general intensity of emotion displayed by these actors played a big part in instilling fear to the learner participants and in recreating the tense moments before the 1896 Revolution began.

In the same manner, the students found it effective that storytelling through dramatization was used as a treatment to teaching history. They described that history lessons were usually delivered to them in a straightforward, detached manner, with textbooks and Powerpoint presentations being used by their teachers as instructional aids to merely transmit historical information to them. In certain parts of their reflection papers and the FGD, their comparison was striking:

The play created life out of words of history textbooks. It gave a human face to history and transcended the traditional treatment of teaching history by merely congesting it to a list of facts, names, dates and places. It reminded the viewers that the superficial teaching of history done by textbooks can never fully depict history as an experience and plight of the generations before us. - Student $\mathrm{Ca}$

Despite its possible limitations, I still believe that its upside is tremendous as a medium because it can actually tell a story or a lesson and indirectly in a way that is fun, engaging, and not forced to the participants through spoonfeeding- Student Ja

One even compared the approach to presentation media such as movies and exhibits and showed the degree to which the RPG was different from them. This was important to note as students only often compared the RPG to traditional, didactic media used by their teachers in class:

Normally, movies and exhibits will give you an overall idea about the Spanish colonization, thus touching the cognitive and affective domains of learning, but in this immersive experience, we were able to know, to feel, and to have a first-hand experience of how the Katipuneros during the time of the Supremo accepted hopefuls.- Student M 
Essentially, the students gravitated toward Katipuneros RPG because of the novel manner of its storytelling, as well as its design and execution. Despite this, the students claimed that Katipuneros RPG was but a supplementary medium only, as they had already been introduced to the topic back in high school and are currently taking or have already taken college courses on Philippines history.

It may be deduced from the data that this dramatized storytelling (RPG content) supported by convincing acting, accurate production design and nostalgic music (RPG form) effectively created and transported learners into a temporally and spatially "make-believe" world (Reiber, 1996), albeit still maintaining commitment to factual historical depiction. These were seen to be contributory to the students' larger appreciation for the Katipunan, which was a topic they already knew extensive information about. Moreover, such feedback from the students bring back the assumptions of Beckem and Watkins (2012) about immersive experiences - that students ought to be actively engaged in social contexts that allow them to link new knowledge with what they previously know about a given topic.

Interactive: allows participation in the created world. Aside from the ability of Katipuneros RPG to recreate time and simulate a world, another important recurring insight from the participants was their level of interaction made possible by the medium. This was an important distinguishing characteristic of the RPG as it was argued previously that the learners mostly encountered passive, presentation media when they were taught history in the past. The students appreciated the medium not only because it immersed them in life affairs during that period but also because it lent itself to insightful interactions with the participants. Learners were able to interact with the cast, placed themselves in the shoes of the Katipuneros and used not only their senses but also their critical and analytical skills in making strategic decisions.

Some students even claimed that the degree of participation necessitated by the RPG was more than what they had expected despite knowing that it was an interactive theater:

Pag sinabing interactive theater, ang impression ko dun, sila 'yung bahala sayo. Magpapadala ka lang.... When it comes to Katipuneros, na-surprise ako kasi ang effective talaga nung ginawa nila.... Instead na kami yung magdedepend sa kanila, kami talaga yung aarte. (I initially thought that in interactive theater, the actors would just drag you around. I was surprised with Katipuneros RPG because instead of us depending on them, we really were the ones acting.) - Student Ai

My initial thought about the Katipuneros RPG is that it would be a play that we would just be dragged around through different rooms, but I was really surprised when we entered, it was like a party and they gave us tasks. We really had to act and get information. - Student $\mathrm{K}$

A number of responses also alluded to the idea that interaction not only with the medium, but, more importantly, with their group mates, was a key factor to succeeding in the game. Given the collaborative nature of the RPG, some students narrated their experiences of working with the group and how significant their bondedness and synergy were to the game. Student Ro shared:

Given the fact that we enter the Bisperas [Katipuneros] as a group, we are expected to exit as a group - without any members being left out. In a sense, it enhances our self-discipline and collaborative skills. We learned to discipline ourselves in order to adapt to the function of the other members of the group... - Student Ro

Such data confirm students' claims that they do find it interesting to engage in immersive and interactive learning experiences and environments, especially in discussing historical concepts. When asked how they wanted history taught to them, most of the students during the group discussion mentioned various levels of participation and interactivity which they hoped their teachers used before. From the vantage point of the students, what seemed to 
AAOUJ 15,1

make Katipuneros RPG a novel tool in the toolbox for learning history was its ability to transcend the interactive media (i.e. entertaining presentations, documentaries, quiz contests and role plays) they had been used to or are currently exposed to. Based on their accounts, Katipuneros RPG offered an interactive world with elements that can be manipulated and a space they can navigate through, which could not be conventionally provided by lecture presentations, textbooks and videos. But it had also gone beyond traditional role-playing, which some students claim they did in history classes before (i.e. social classes, Noli Me Tangere and El Filibusterismo) as Katipuneros RPG equipped a theatrical performance with game elements - exceeding the expectation that students only had to act. Instead, they had to both act and play with others, collaboratively thinking and doing tasks in order to learn history. These data seem to confirm the claims of Stoffers (2011) and Aja et al. (2017) about multisensorial learning; through the stimulation of senses, individuals become exposed to meaningful, collaborative and exciting experiences.

Intrinsically motivating: sustaining participation in the created world. Reiber (1996), in his article, seriously considering play - designing interactive learning environments based on the blending of microworlds, simulations and games, cited intrinsic motivation as a defining attribute of play. He argues that for play to be effective, it has to be "pleasurable for its own sake and ... not dependent on external rewards." Data from students' reflections validate this characteristic as they saw Katipuneros RPG as a learning medium that challenged them, compelled them to be competitive and made them lose track of time and space.

Some commented on the challenging nature of the Katipuneros RPG, which motivated them to continue and, eventually, finish the game. The researchers agree that there may be external motivators at stake; some of them were promised grade incentives by their professors if they participated in the event. Professors in the university often invite students to cocurricular activities to augment or supplement lessons taught inside the classroom. Nevertheless, it was evident from the data that the students found the problems and tasks in the Katipuneros RPG to be effective in engaging them as learners, as well as the feeling of achieving the outcome of the task at hand. Student Eu states:

It also effectively teaches values in a way that it presents outcomes of your own actions and how it could possibly lead you to the ending you will get. - Student Eu

In addition to the sense of accomplishment the students felt as a consequence of immersing in the created world of Katipuneros RPG, some students also found themselves feeling rewarded not from the outcome of an accomplished task or reaching the end of the gameplay but from the act of playing the game itself. Some were willing to forgo some of the privileges and activities they enjoy, like using their mobile phones when they need it or the freedom to ask questions. In other words, there is a thrill of being punished but not one that is interruptive and would impair their learning, rather, one that would keep them playing in the game. Reiber (1996), citing Deci (1985), Lepper and Malone (1987) and Malone and Lepper (1987) describes this in the same paper, arguing that an environment is intrinsically motivating if learners see participation not as a means to a reward but the reward itself. The researchers found thematic similarities between some of the students' reaction to Katipuneros RPG and Reiber's argument:

I was so caught up in the moment and I did not even realize that I was learning so much about history by just going out there and have fun. - Student Ja

Parang nag-stop po 'yung time.... As students, we were probably worrying about other subjects, pero nung na-immerse po kami dun sa community ng Katipuneros ... 'yung emotions po namin napaglaruan. (It was as if time stopped. We were students probably worrying about other subjects, but when we were immersed in Katipuneros RPG, it was as if they played with our emotions.)- Student Ji 
Reiber's defense of intrinsic motivation drew heavily from Mihaly Czikszentmihalyi's flow theory (1990). This theory on human motivation argues that individuals feel an extreme sense of satisfaction derived from being "so engaged and absorbed by certain activities that they seem to "flow" along with it in a spontaneous manner" (Reiber, 1996, p. 48). Flow, as defined by Czikszentmihalyi (in Reiber, 1996, p. 48), is defined as: “. . the state in which people are so involved in an activity that nothing else seems to matter; the experience is so enjoyable that people will do it even at great cost, for the sheer sake of doing it." This seemed to be the case with the quotes from the students as they felt that they were temporally and spatially divorced from the world for a moment because of being too engrossed in the activity.

Another interesting account from one of the students was the degree to which reality had been blurred by their immersion in (and consequent pleasure from) Katipuneros RPG. Student Sy claimed to have observed this even before the game started as soon as they were alighting the jeepney they rode to the venue. She said, "Kakababa pa lang namin ng jeep, sinabi nung emcee "Bilisan nyo!' (We just got off the jeepney when the emcee shouted, "Hurry up!")

Throughout the course of the game, she with her groupmates' participation manifested various reactions due to the actors' treatment and interaction with them. In real life, the actors might not really be as angry or as friendly as how they acted in the game, but their splendid portrayal of the characters was enough to trigger emotional and physical reactions on the part of the participants. In a way, this was similar to another comment from student Ja, who joked about how he lied his way through the perya (fair) just to avoid getting caught:

Nakakabadtrip 'yung mga characters, pero 'yun 'yung way para masabi na effective talaga sila. Natatouch nila 'yung inis mo, 'yung mga ibang characters sobrang taray, 'yung iba naman ïrapan ka. (I was annoyed at the characters, but that just proved the effectiveness of their acting. They made you feel angry at them for being really snobbish.)- Student Sy

The environment and setting created by the RPG willed me to act like a Filipino peasant during the Spanish era by imitating the way they behave, talk, and act towards guardia civils whenever they confront me. Hilarious moments also ensue in certain situations like being forced to make excuses, no matter how stupid or out of place they are to avoid getting sent by the guards to jail.- Student Ja

Most revealing from Student Sy's accounts, however, was what she observed after Katipuneros RPG. She claimed that the event really had "long-lasting impacts" on her and the friends she went with to the event, which showed as soon as they stepped out of the venue and headed home:

... long-lasting siya kasi right after noon naglakad kami . . . tapos habang naglalakad kami, si Ji (classmate) ... bigla siyang sumigaw ng 'Ano'ng pagpupulong 'yan?' Nagulat talaga kami! Doon mo narealize na cool kasi nadala namin kung ano yung experience namin doon hanggang doon sa kinakainan namin, pinag-uusapan pa rin namin siya. (The effect was long-lasting. While we were walking, Ji shouted (in guardia civil tone), "What is this commotion about?" We were caught off guard! So that's when I realized how cool the experience was, because even when we got to the place where we had dinner, we were still talking about it.)

In a way, Katipuneros RPG was not only able to create a world of its own and allowed sufficient, meaningful interactions between this created world and the learners it was also structured in a way that effectively focused the learners' thought processes, emotions and actions into the game - so much so that these "leaked" to the outside world as soon as the game concluded. Contrasting the medium, yet again, to didactic, passive media they used in history classes, Katipuneros RPG provided a refreshing platform for learners to be constantly challenged from within the learning system and be immensely engrossed in the tasks at hand. Such medium allows them to learn with a sense of excitement, passion and satisfaction and frees them from the thinking that learning is a chore that one must overcome. 


\section{AAOUJ}

15,1
Students mentioned that Katipuneros RPG was more targeted toward the affective domain instead of the cognitive domain. The affective domain of learning includes changes in beliefs, emotions and opinions of learners, while the cognitive domain of learning zeroes in on knowledge gain (Cadiz, 2003). Because the students claimed to already be familiar with objective facts about the Katipunan before engaging in Katipuneros RPG, the experience was a way for them to "re-learn" these events, in a way entering a cycle of relate-understandrealize, where the students relate the lessons to class discussions and understand the relevance of the gamified experience through such prior knowledge. All these are integrated to come up with a larger realization about this portion of Philippine history, such as discovering the emotional weight and the responsibility that came with being a member of the group, the fear of baseless arrests, the dilemma of killing an infidel and the courage to lie to protect your fellow Katipuneros.

But while they pointed out that it was a novel learning experience, they felt that it also could not offer the affordances to cognitive learning that more didactic media, like a lecture presentation, for instance, could provide:

Just as previously stated, I think Katipuneros RPG is an interactive media that allowed for participatory learning about history. I think it can be considered a supplementary medium for the typical classroom setup of learning of history. Credible history books and history teachers thought provide us a more pieced together idea of history. - Student L

To add po, wala po akong natututunan doon sa mga pinapahanap nila na mga sagot sa tanong. Pero 'yung experience, tumatak. (I did not really learn anything from the things they quizzed us about. But the experience really left a mark.) - Student $H$

Essentially, Katipuneros RPG focused more on the simulated experience and less on cerebral input. Because of this, the students mentioned that perhaps it would be beneficial if there were post Katipuneros RPG discussions so that they could appropriately level off and process their experiences.

\section{Skills that contributed to the achievement of goals}

Gamified learning provides different kinds of contexts and environments for learners. In order to achieve the goals of Katipuneros RPG, the learners highlighted different skills that were necessary in completing the tasks. These skills can be categorized into five, namely critical and creative thinking, communication, collaboration and leadership. It is interesting to note that these skills reflect the $4 \mathrm{C}$ 's of 21 st century skills (critical thinking, creativity, communication and collaboration) that students should possess to be successful in a global environment (National Education Association, 2012).

As an immersive and gamified learning activity, Katipuneros RPG offered personalized experiences for each learner. It relied upon problem-based learning approaches and critical and creative thinking skills of the learners. According to the learners, critical thinking entails selfreflection and creativity in decision-making. Meanwhile, creative thinking refers to "thinking outside the box" in solving problems. Some learners noted that information for a given task was not given to them completely; so, they needed to be creative in developing strategies and solutions to accomplish the tasks. These skills were highlighted when they were presented with challenges that entail careful analysis of the situations, systematically addressing the issues and problems presented, adopting new ideas and making reasoned judgment.

Apart from critical and creative thinking, communicating effectively with colearners and other key players in a given learning situation was an essential facilitating factor in Katipuneros RPG. The learners articulated their thoughts and ideas effectively through oral and nonverbal communication. Because they did not have any idea about the tasks and the activities that will be given to them, some learners noted that their skills in improvisation 
were further developed. During the play, the learners interacted with the characters and performed by singing, dancing and role-playing.

Meanwhile, Katipuneros RPG fostered collaboration or working creatively with other colearners in teams to reach a goal and complete specific tasks. As one learner observed, they were encouraged to work in teams and cooperate during the entire play. In fact, in order to fulfill the goal of becoming a Katipunero, each group member makes sure that every member actively engages in the learning process. As a result of collaboration, the learners noted that their leadership skills also contributed to their performance in the play. Some participants stepped up and assumed the role of group leader during the activities. They demonstrated their initiative, trust and resourcefulness and fostered unity and camaraderie among group members.

\section{Insights gained from the experience}

Aside from the skills that the participants had to exhibit in order to accomplish the goals of the play, they were also able to gain important insights as a result of going through the experience.

Awareness of rights. The Katipuneros RPG learning experience helped some of the participants become more aware of the rights of the Filipinos at the time of the revolutionary movement. After the activity, student Eu realized that because of what happened in the past, "we have advanced and reached a point wherein our values are heightened and that we are aware of our rights..."

The participants also noted that Filipinos at that time were courageous in fighting for their rights, even if the chance of victory was bleak. Student C claimed that "despite the physical, mental and emotional torture" that they would have to go through, the idea of "reclaiming our natural rights" to our country fueled and sustained the revolutionaries' fire for liberation. Thus, awareness of their rights was not only an outcome of going through the Katipuneros $\mathrm{RPG}$ but was also recognized as the reason for the revolutionaries' courage.

Appreciation for what the Katipuneros have done. There was a unanimous realization of the value of what these revolutionaries have done. Student K captured the sentiment when she said "I feel proud and thankful that if it is (was) not for them, for their sacrifices that they do (did) for our country, we will not be enjoying what we have now in our lives." This realization naturally segued into a feeling of nationalism and a willingness to make their own sacrifices for others and for the county. "I feel motivated to do better in everything that I do despite the challenges and problems that I will encounter in my life, for the sake of my family and for my country.”

Sense of community. Katipuneros RPG highlighted the sense of community among the participants because they had to go through the different tasks as a team. Moreover, they also realized that Filipinos have a strong sense of community, brotherhood and camaraderie. Going through Katipuneros RPG, the participants were willing to defend and look after each other, just as the Katipuneros did during colonial times. Student A said that it was in our culture to do so.

Shifting values. Participants reflected on an encounter with the characters of the play during the initiation rites into the Katipunan where they were asked to kill a traitor of the movement. A number questioned this because they felt that to kill another person was not the right thing to do. They belatedly realized that "apparently, in order to become a Katipunero we had to do the gruesome act in order to prove our loyalty to them but in our case we did not do it... we thought... Killing was an act that should not have been condoned." It challenged their principles. Mercy or loyalty? Reflecting on this, they realized that "moral codes are fickle." Some had to ask their history professor about this, to which he answered that people at the time had radically different mindsets and different contexts compared to the present. 
AAOUJ 15,1

The participants' questioning of the changing morals and values point to the importance of providing a space for debriefing and reflection for the participants of immersive and interactive learning activities, such as the Katipuneros RPG. This becomes particularly valuable considering the constructivist principles that the play is based on.

\section{Conclusions and recommendations}

Results of this research showed that Katipuneros RPG, with its immersive, interactive and intrinsically motivating features, plus its powerful storytelling, provided its participants a unique experience in learning history that a traditional, lecture-type set-up lacked. History lessons, which were often taught through identification and memorization, are presented to students in a participatory and experiential approach, wherein learners take on a more active role as the so-called "teacher" vanishes from view in lieu of a learning system where students can think, move around and work together. In this system, the lines demarcating actors from players are made obscure as participants themselves become actors in a gamified theater.

The play-based theater was also effective in making the participants exhibit 21st century skills, such as critical and creative thinking, communication, collaboration and leadership. Moreover, it provided an avenue for the participants to not only relive that particular time in history but also to reflect on and question the values and principles espoused during that time. The latter reflects social constructivist principles on which the play was based.

Teaching history through immersive and gamified learning activities such as the Katipuneros RPG with underlying constructivist principles and a particular emphasis on the affective domain seems particularly necessary, especially in the current socio-political context of the country. The persistent presence of national issues, such as extra-judicial killings, martial law, among others, continues to dominate the public sphere, affecting and engaging the youth. To teach history, not only with a goal to impart concepts but to invite students to see its implication to the current times and most especially to put into perspective the lives and condition of our present realities, is a challenge that could be addressed by an immersive and gamified theater like Katipuneros RPG.

This research contends, however, that while Katipuneros RPG had strong potential in teaching history, its current design would be more appropriate as a supplement to lectures and traditional teaching methods. For one, Katipuneros RPG presumes that students have prior knowledge on historical events which they should harness in order to advance and succeed in the game. Therefore, its main goal is not so much to impart new information as it is to enhance existing knowledge and deepen students' appreciation of history. Similarly, Katipuneros RPG could provide synthesis to the lessons discussed in the lecture and even function as an assessment of student learning. Nonetheless, a play-based learning system like Katipuneros RPG, which melds principles of problem-solving, theater and game, could be a stand-alone learning system for a different topic and content.

Finally, Katipuneros RPG's design can be appealing to the youth. Its gamified design and its philosophy of experiential and "enjoyable" learning capture the interest of youth learners who may possess a paltry level of attitude toward learning their history.

This research recommends the following to improve the design and offering of Katipuneros RPG. These are guided by the comments and observations noted by our study participants.

(1) Improve the simulation by adding layers to the storyline, inviting more effective actors to facilitate the game, introducing additional controlled risks and designing a more realistic set.

(2) Properly introduce the game through a detailed orientation of its goals, rationale and context. A brief discussion on relevant historical events and individuals may be added 
as well. The tasks that players need to complete should also be comprehensively discussed in the orientation.

(3) Make possible learning of new information by adding more inputs, trivia and explanation while performing the tasks or upon the completion of the challenges.

(4) Provide opportunities for reflection and synthesis, such as through a post-game debriefing, where learners are invited for a guided discussion to share their learning, questions and insights about their experiences.

(5) Take inspiration from Katipuneros RPG when designing more role-playing games about contemporary socio-political issues in the country.

\section{References}

Agoncillo, T.A. and Mangahas, F.B. (2010), Philippine History, C\&E Publishing, Quezon City, Philippines.

Aitken, V. (2013), "Dorothy Heathcote's mantle of the expert approach to teaching and learning: a brief introduction", Ch. 3 in Fraser, D., Aitken, V., and Whyte, B. Connecting Curriculum, Linking Learning, available at: https://www.mantleoftheexpert.com/wp-content/uploads/2018/01/ MOTE-Chapter-3_Aitken_Pages-from-Connecting-Curriculum-Fraser- v3-220213.pdf.

Aja, S.N., Eze, P.I., Igba, D.I., Igba, E.C., Nwafor, C.C. and Nnamani, S.C. (2017), "Using multi-sensory instruction in managing classroom for effective teaching and learning", International Journal of Applied Engineering Research, Vol. 12 No. 24, pp. 15112-15118. available at https://www. ripublication.com/ijaer17/ijaerv12n24_163.pdf.

Amineh, R.J. and Asl, H.D. (2015), Review of constructivism and social constructivism, Journal of Social Sciences, Literature and Languages, Vol. 1 No. 1, pp. 9-16, available at https://pdfs. semanticscholar.og/3890/3f4a7255496f75124d639e14e9b810c17370.pdf.

Beckem, J.M. and Watkins, M. (2012), "Bringing life to learning: immersive experiential learning simulations for online and blended courses", available at https://files.eric.ed.gov/fulltext/ EJ1000091.pdf.

Bouko, C. (2014), "Interactivity and immersion in a media-based performance. Participations", Journal of Audience and Reception Studies, Vol. 11 No. 1, available at: https://www.participations.org/ Volume $\% 2011 /$ Issue $\% 201 / 15$.pdf.

Bucknall, J.J. (2017), "The 'reflective participant,' '(Remember)ing' and '(Remember)ance': a (Syn) aesthetic approach to the documentation of audience experience", PARtake: The Journal of Performance as Research, Vol. 1 No. 2, Article 6, available at: http://scholar.colorado.edu/ partake/vol1/iss2/6.

Cadiz, M. (2003), Educational Communication for Development (Basic Concepts, Theories and KnowHow), Revised ed., College of Agriculture, UP Los Banos, College, Laguna.

Cook, M.P., Gremo, M. and Morgan, R. (2017), "Playing around with literature: tabletop role-playing games in middle grades ELA", Voices from the Middle, Vol. 25 No. 2, pp. 62-69. available at: https://www.ncte.org/library/NCTEFiles/Resources/Journals/VM/0253_dec2017/VM0252 Playing.pdf.

Corfield, P.J. (2008), All People are Living Histories - Which is Why History Matters, Institute of Historical Research, available at: https://www.history.ac.uk/makinghistory/resources/articles/ why_history_matters.html.

Evans, S. (2013), "Personal beliefs and national stories: theater in museums as a tool for exploring historical memory", available at: doi: 10.1111/cura.12019.

Fatih, Y., Kumalija, E.J. and Sun, Y. (2018), "Mobile learning based gamification in a history learning context", in Sanchez, I.A. and Isaias, P. (Eds), 14th International Conference Mobile Learning 2018, pp. 143-147, available at: https://files.eric.ed.gov/fulltext/ED590271.pdf. 
AAOUJ 15,1

Figg, C. and Japal-Jamani, K. (2009), "Engaging 21st century learners and differentiating instruction with technology", available at: https:/www.researchgate.net/publication/318749951_Engaging _ 21st_Century_Learners_and_Dif ferentiating_Instruction_with_Technology.

Kaiko, E.S. (2015), "The play is the thing: gamifying the theatergoing experience", doi: 10.7916/ D85D8R36.

Kim, B. (2015), “Understanding gamification”, Vol. 51 No. 2, American Library Association, available at: https://journals.ala.org/ltr/issue/download/502/252.

Li, Q., Zhang, T., Wang, B. and Wang, N. (2013), "Effects of RPG on middle school players' intrapersonal intelligence", in Pan, Z., Cheok, A.D., Müller, W. and Liarokapis, F. (Eds.), Transactions on Edutainment IX, Lecture Notes in Computer Science, Springer, Berlin, Heidelberg, pp. 160-175.

National Book Development Board (2017), "Readership survey: reading behavior and patterns of purchase", available at http://booksphilippines.gov.ph/readership-survey-reading-behavior-andpatterns-of-purchase/.

National Education Association (2012), Preparing 21st Century Students for a Global Society: An Educator's Guide to the Four Cs, Washington, DC, Author, available at: http://www.nea.org/ assets/docs/A-Guide-to-Four-Cs.pdf.

Philippine Educational Theater Association (2019), "Our company, our story”, available at: https:// petatheater.com/about.

Randi, M.A.F. and Carvalho, H.F. (2013), "Learning through role-playing games: an approach for active learning and teaching", available at: http://www.scielo.br/scielo.php?script $=$ sci arttext\&pid=S0100-55022013000100012.

Richardson, K. (2013), Initiation Rites, C. 1896. Katipunan: Documents and Studies, available at: http:// www.kasaysayan-kkk.info/membership-documents/initiation-rites-c-1896.

Rieber, L.P. (1996), "Seriously considering play: designing interactive learning environments based on the blending of microworlds, simulations, and games", Educational Technology Research and Development, Vol. 44 No. 2, pp. 43-58.

Schipper, I. (2017), "From flaneur to co-producer", in Leeker, M., Schipper, I. and Beyes, T. (Eds), Performing the Digital: Performativity and Performance Studies in Digital Cultures, available at: https://oapen.org/download?type $=$ document $\&$ docid $=627661$.

Schwartz, M. (2012), Best Practices in Experiential Learning, available at: https:/www.ryerson.ca/ content/dam/lt/resources/handouts/ExperientialLearningReport.pdf.

Stoffers, M. (2011), Using a Multi-Sensory Teaching approach to impact Learning and Community in a Second Grade Classroom, Theses and Dissertations, Vol. 110, available at: https://rdw.rowan. edu/etd/110.

Tanis, D. (2012), Exploring Play/playfulness and Learning in the adult and Higher Education Classroom, available at: https://etda.libraries.psu.edu/files/final_submissions/8092.

Zosh, J.M., Hopkins, E.J., Jensen, H., Liu, C., Neale, D., Hirsh-Pasek, K., Solis, S.L. and Whitebread, D. (2017), Learning through Play: a Review of the Evidence (White Paper), The LEGO Foundation, DK, available at: https://www.legofoundation.com/media/1063/learning-through-play_web.pdf.

\section{Corresponding author}

Elijah Jesse Mendoza Pine can be contacted at: ejmpine@devcom.edu.ph

For instructions on how to order reprints of this article, please visit our website:

www.emeraldgrouppublishing.com/licensing/reprints.htm

Or contact us for further details: permissions@emeraldinsight.com 